\title{
Effect of Special Cognitive-Behavioral Intervention on Commitment to Exercise and Mental Health
}

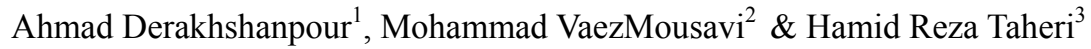 \\ ${ }^{1}$ PhD Candidate, Sport Psychology, Imam Reza International University, Mashhad, Iran \\ ${ }^{2}$ Professor, Imam Hossein University, Tehran, Iran \\ ${ }^{3}$ Professor, Ferdowsi University of Mashhad, Mashhad, Iran \\ Correspondence: Ahmad Derakhshanpour, PhD Candidate, Sport Psychology, Imam Reza International University, \\ Mashhad, Iran. E-mail: ahmad_derakhshanpor@yahoo.com
}

Received: February 17, 2018 Accepted: March 28, 2018 Online Published: April 11, 2018

doi:10.5539/gjhs.v10n5p78 URL: https://doi.org/10.5539/gjhs.v10n5p78

\begin{abstract}
Background: Although most people are aware of the advantages of physical exercise, they have failed to commit to it. This forms justification for this intervention.
\end{abstract}

Objectives: In this study, the effect of special cognitive-behavioral intervention on commitment to exercise and mental health in adults was investigated by controlling the role of the commitment-to-exercise variable.

Methods: The statistical population for this study comprised 635 employees with over 10 years' professional experience: 235 were selected from amongst these. Thereafter, 80 employees were randomly assigned to two groups - experimental and control - of 40 each. The experimental group was trained for four months in fourteen sessions for using cognitive-behavioral therapy. To collect data, a commitment-to-exercise and mental health questionnaire was used.

Results: When the effect of the pretest variable on the dependent variable was adjusted, it was observed that there is a significant difference $(\mathrm{p}<0.01)$ between the means of the scores for commitment and mental health. The covariance test revealed that the difference in the mental health of the experimental and control groups after controlling the effects of commitment to exercise was not significant $(\mathrm{p}<0.05)$.

Conclusion: It can be concluded that commitment to exercises can be improved in individuals by using the aforementioned cognitive-behavioral protocol. Furthermore, using the mediating role of commitment to exercise improves mental health. Therefore, counselors and therapists can use the cognitive-behavioral intervention protocol to improve the commitment to exercise and the mental health of individuals.

Keywords: cognitive-behavioral intervention, commitment, mental health, exercise, protocol

\section{Introduction}

Exercise causes numerous physiological or psychological changes. Physiological effects of exercise can include an increase in endorphin levels (Fuss, 2015), neurotransmitter production (Clark \& Mach, 2016, de Coverley Veale, 1987), and attenuation of the hypothalamic pituitary-adrenal (HPA) axis response to stress (Clark \& Mach, 2016). Psychological effects may include a distraction from feelings of depression and anxiety (Deforche \& De Bourdeaudhuij, 2015) and positive feelings associated with mastery and self-efficacy (Middelkamp, 2017). Early-onset depression was found to be associated with obesity (Quek et al., 2017). The underlying mechanism is related leptin which is a hormone that regulates energy balance by inhibiting appetite. Chronic stress leads to down-regulation of lepin receptor and weight gain (Yang et al., 2016). The down-regulation of leptin signaling is associated with depressive-like behavior and cognitive impairment facing chronic stress (Yang et al., 2016). Considerable scientific evidence suggests that inflammation and inflammatory diseases contribute to mood disorders and poor mental health. The blood levels of pro-inflammatory markers including TNF- $\alpha$ and IL-6 were significantly higher in patients with depression than controls (Liu et al., 2012) and the increase in pro-inflammatory cytokines leads to coronary artery disease (Ho et al., 2010). Antidepressants (Lu et al., 2017) and exercise (Nascimento et al., 2014) promote reduction in pro-inflammatory cytokines. Exercise may help to lower inflammation and be beneficial in contributing to better mental health outcomes in patients who suffer from 
inflammatory disorders (Abd El-Kader, 2016). Yet, as the general health mediator, the low rate of participation in sport exercises comprises the principal restriction on physical activities (Tiedemann, Sherrington, \& Lord, 2011).

Consequently, many people continue avoiding exercise. Lack of time, energy, and motivation are among the excuses they bring for being sedentary (Jouper \& Hassmén, 2009). With the advent of positive thinking psychology and the theory of hope and commitment, numerous educational, research, and therapeutic interventions have been used to investigate their influence on positive behavioral dimensions and traits (Snyder, Cheavens, \& Michael, 2005). Commitment is a feeling of attachment and belongingness to some particular behavior, indicating the level of perseverance in and adherence of the individuals to continued participation in the target behavior (Sousa, Torregrosa, Viladrich, Villamarín, \& Cruz, 2007). Commitment to sport is the additive effect of the degree to which an individual enjoys participation in sports, invests personal resources (i.e., time, effort, money) in sports, perceives that sports provide valuable opportunities, and is supported in participation by his/her significant others (Scanlan et al., 2013). Brickman proposed that the nature of commitment involves a functional element and an obligatory element. Put alternatively, individuals continue their efforts either because they want to or because they have to. Specifically, individuals can at any moment stay actively committed to both the functional and obligatory elements while the level can be fluctuating or changing (Brickman, Sorrentino, \& Wortman, 1987). Enthusiastic and constrained commitments indicate the functional and obligatory variants of commitment. In the sport commitment model, the indirect support for the distinction between enthusiastic commitment and constrained commitment can be seen in the controlled and independent motivations of the self-determination theory. Research indicates that regular self-determined behavior (in such areas as education, occupation, and sport) leads to better mental health (Ryan \& Deci, 2000) in people's life, while controlled motivations indicate that one is convinced or forced (Deci \& Ryan, 2008). However, individuals' motivation for change and resistance to altering unhealthy habits must be considered when developing an effective approach to counseling (Stonerock \& Blumenthal, 2017).

Weiss, Kimmel, and Smith proposed a model for sport commitment where sport enjoyment has been introduced as the key factor and mediator for sport commitment. Based on the sport commitment mediation model, any factor that increases enjoyment and interest in physical activity can make individuals want to continue participating in that activity (Weiss, Kimmel \& Smith, 2001). Mental health is a stage in well-being where individuals are able to recognize their abilities, overcome the stresses typical in life, and become positively efficacious for themselves and the society (Asztalos, De Bourdeaudhuij, \& Cardon, 2010). Although the majority of people working very actively to gain access to health procedures are aware of the benefits of exercise for physical and mental health, they have thus far failed to enjoy sport-related health benefits. This adds to the importance of and need for development of some form of intervention aimed at increasing exercise among people (Brug, Oenema \&Ferreira 2005). Typically, to achieve this aim, socio-cognitive behavioral theories are used (Ajzen, 1991). The phrase cognitive-behavioral training emphasizes the fact that thinking processes are as important as environmental effects (Epstein \& Baucom, 2002). Cognitive-behavioral training programs are effective in the development and promotion of such capabilities as decision-making, creating motivation, assuming the responsibility for establishing positive relations with others, success, creating self-esteem, problem-solving, self-regulation, self-efficiency, and mental health (Sukhodolsky, Kassinove, \& Gorman, 2004). Studies have identified mediating variables as the potential mechanisms by which a variable may be related to another variable or probably be influenced by intervention (Brassington, Atienza, Perczek, DiLorenzo, \& King, 2002).

For example, in studies by Brovold et al. and Millstein it was indicated that a combination of interventions through counseling and medical recommendation along with exercise could significantly affect the adherence to exercise, quality of life, and mental health of patients (Brovold, Skelton, \& Bergland, 2012; Millstein et al, 2016). Applying special interventions, Markland and Tobin investigated the relationship between the support for psychological needs and internalization of regular exercise behavior. Finally, it was established that individuals are less in need of external motivation and scheduling when the need for supporting self-determination and social assimilation is developed (Markland \& Tobin, 2010). In another study, Ingledew et al. evaluated the effect the role of exercise motives had on mental gains: these gains lead to goal satisfaction. They also revealed that controlled regulation had negative impact on exercise satisfaction (Ingledew, Markland \& Strömmer, 2014). Scanlan et al. suggested that appreciation of competency in exercise affects enjoyment of sport and it is a major contributor to sport commitment (T. K. Scanlan, Chow, Sousa, L. A. Scanlan, \& Knifsend, 2016).

American Sports Medical and Health Forum confirms that the greatest potential for health and reduced mortality is enhanced physical activity (Haskell et al., 2007). Despite the numerous advantages of exercise, the rate of participation in sport training is low. Over half of people do not exercise. This low rate creates problems, such as increased risk of heart diseases (Darlow \& Xu, 2011). Therefore, using intervention methods to help these people 
is necessary since as of yet no experimental study has been conducted to combine counseling and commencement of sport exercises (Brovold et al., 2012). Moreover, no study has investigated the cognitive-behavioral therapy, which is an effective method to improve psychological traits necessary for improving the commitment to exercise and its effect on the mental health of adults. This study seeks to fill this research gap: its aim is not only to control the moderating role of the variable commitment to exercise, but also to investigate the effect of the special cognitive-behavioral intervention on commitment to exercise and mental health in adults.

\section{Research Method}

\subsection{Participants}

The statistical population for this study comprised the entire 635 male and female employees aged 38-56 working for the Personnel Department of the Zob Aahan Esfahan Factory with over 10 years' experience. Statistical sample of this study included 235 employees: these were selected based on Morgan's Table (Krejcie \& Morgan, 1970) using stratified random sampling. Then, using the scores from a homogeneous questionnaire for commitment to exercise and mental health, 80 of them were selected and randomly assigned to two groups-experimental and control of 40 each. The mean age of the participants was 44.5 years, comprising 56 males (70\%) and 24 females $(30 \%)$. Their educational qualifications were: high school diploma (37.5\%), an Associate of Science degree $(13.5 \%)$, and Bachelors and higher degrees (49\%).

\subsection{Tools}

The following instruments were used to measure the independent variable (i.e. cognitive-behavioral intervention) and the dependent variable (i.e. commitment to exercise and mental health) respectively.

1). Commitment-to-Exercise Questionnaire: The researcher-developed commitment-to-exercise questionnaire had a four-factor structure. These factors were: enthusiasm for exercise, exercise intensity and frequency, reinforcement, and disruption. The construction validity of the questionnaire was investigated using factor analysis and the principal components method (with a sampling adequacy index of 0.769). After applying exploratory factor analysis for five times, 10 questions were deleted due to improper factor loading. Ultimately, the final copy of the commitment-to-exercise questionnaire with 25 questions on four dimensions with a special value of larger than one explained a total $58.409 \%$ of the questionnaire variance. In order to ensure the results of the exploratory factor analysis, the confirmatory factor analysis was done using LISREL. The chi square-to-DF ratio was 1.6; other LISREL output indices indicate the proper fitness of the second-order commitment-to-exercise questionnaire.

Furthermore, based on a t-value of over 1.96 obtained for all indices, the significance model test indicated that the path indices for the above model were completely significant and that the dimensions identified in the exploratory analysis were confirmed. This instrument was scored on the Likert scale with 5 divisions ranging from 1 for "never" to 5 for "always". The Cronbach's alpha obtained was 0.873 : this validated the reliability of the questionnaire by using internal consistency. This, in turn, generally indicated that the commitment-to-exercise questionnaire with satisfactory reliability and validity indices can be used as a suitable instrument for evaluation of commitment to exercise by psychologists and counselors in cognitive-behavioral interventions (Derakhshanpoor, Vaez Mousavi, $\&$ Taheri, 2016).

2). General Health Questionnaire: The General Health Questionnaire designed in 1979 by Goldberg and Hillier was used to measure mental health. This instrument contains 28 items with a four-division scale including physical signs, signs of anxiety and sleep disorder, social dysfunction, and depression scale (Goldberg \& Hillier, 1979). In a study involving validation of the 28-item GHQ, Palahang et al. reported a cutoff score of 6 based on a traditional scoring, and a cutoff score of 22 based on the Likert scale with a reliability index (Test-Retest method) of $91 \%$ (Palahang, Nasr, \& Shahmohammadi, 1996). In this study, the validity index was 0.859 using Cronbach's alpha.

\subsection{Training Protocol}

\section{Special Cognitive-Behavioral Intervention}

The cognitive-behavioral therapy was developed by the researchers by reviewing the theoretical foundation and considering the traits of the participants committed to exercise. The theoretical foundation emphasizes using such components as enthusiasm for exercise, intensity and frequency of exercise, reinforcing, and disrupting factors. These factors are based on the Health Belief Model Theory (Becker, 1974), Trans-theoretical Model (Richard, Christina, Deborah, Rubio, \& Kennon, 1997), Planned Behavior Theory (Sukhodolsky, et al, 2004), and Self-determination Theory (Weiss, et al, 2001). Based on these theoretical foundations, fourteen 70-minute sessions of cognitive-behavioral therapy were designed. Then, the experimental group was trained using 
cognitive-behavioral therapy while the control group was put on the waiting list. The details of intervention on the cognitive-behavioral intervention group broken down for each session were as follows.

In session 1, following the meeting and establishment of good relations, the importance and aim of the cognitive-behavioral therapy were stated and the problems of the clients were formulated using a cognitive-behavioral approach. Session 2 was centered on the importance of giving priority to health and physical fitness standards and its status in life. Session 3 stated the importance and urgency of commitment to exercise, the techniques for starting a sport activity, and dominance over behavioral signs. Session 4 involved recording ideas, cognitive errors, struggle with negative thoughts including locating negative self-items, and training to replace them with positive self-items. Session 5 consisted of thought management skills, feeling and behavior in different situations, and the struggle to enjoy rather than to seek perfectionism. Session 6 was spent in changing and correcting myths, including location of self-concepts, previous learning, as well as questioning and clarification of beliefs. Session 7 comprised acquisition of social skills and skills for reinforcing relations with friends for formation of an exercise village. Session 8 involved training to prepare the environment for exercise. Session 9 witnessed improvement of emotional intelligence and teaching techniques to develop exercise habits. Session 10 comprised teaching techniques to set a goal, self-plan, self-regulate, and learn practical skills. Session 11 was premised on teaching improvement of self-evaluation and self-supervision. Summarizing all these previous sessions, session 12 taught the techniques of self-control and self-determination. Session 13 comprised a discussion of time management, overcoming obstacles, relapse prevention, and adoption of coping strategies. Session 14 addressed a balanced attitude, achievements of the participants, and using alternative strategies, and, finally, saw participants briefly go over the literature from previous sessions and exercising the learned procedures. Furthermore, the experimental group was recommended to exercise at least four sessions a week, each a minimum of half an hour. Types of exercises - included joining a gym, swimming, hiking, or any other activity of their interest - were specified depending on the interests of the participants.

\subsection{Data Collection}

The statistical methods used in this study were descriptive and inferential. The results of the data from variables of research and intervention therapy were described using descriptive statistic methods. Then, the statistical assumptions required for using the parametric MANCOVA and ANCOVA tests, including Kolmogorov-Smirnov, Shapiro, and Wilk test to verify the normal distribution of scores in the sample group of the population, Levine's test to verify equality of variances, ETA coefficient for the linear relation between the pretest and posttest, and Box's M test for equality of the covariance of the dependent variables were analyzed. Further, the effect of pretest and the concomitant variables using ANCOVA and MANCOVA was controlled. Finally, the research hypotheses were analyzed using the statistical method for covariance and t-test to compare the means of two independent groups and for analysis of variance to compare the means of several independent groups.

\section{Results}

Assumptions for the multiple-variable covariance were evaluated prior to data analysis. In this respect, the results of the Kolmogorov-Smirnov, Shapiro, and Wilk tests were significant for none of the variables. The findings also revealed that the normality assumption did hold. Further, the results of Box's M test and Levine's test were not significant. The findings indicate that the assumption of equality for covariance matrices and the assumption of equality for variances of the posttest scores of dependent variables in both experimental and control groups do hold. Another assumption for covariance analysis is the homogeneity of the regression between the pretest and posttest variables in both the experimental and control groups. The $\mathrm{F}$ values and significance level indicate that the type and relation slope between the pretest and posttest variables and the regression lines for each variable in both the experimental and control groups were uniform and that there is no significant relation between them. The ETA coefficients between the pretest and posttest scores in the dependent variables were all significant, indicating the linearity of the relations. Further, the correlation between the pretest and posttest scores for commitment to exercise was 0.716 and for mental health was 0.797 . Therefore, there is a high correlation between the pretest and posttest. Consequently, another important assumption also holds. Since the dependent variables in this study have been measured in both the experimental and control groups by initially using descriptive statistical methods, the indices tending toward the center as well as the dispersion have been calculated and described. 
Table 1. Mean and standard deviation of pretest and posttest scores in both groups

\begin{tabular}{|c|c|c|c|c|c|c|}
\hline \multirow{2}{*}{ Variables } & \multirow{2}{*}{ Groups } & \multicolumn{3}{|c|}{ Pretest } & \multicolumn{2}{|c|}{ Posttest } \\
\hline & & $\mathbf{N}$ & Mean & SD & Mean & SD \\
\hline \multirow{2}{*}{ Commitment To Exercise } & Experimental & 40 & 2.63 & 0.54 & 3.54 & 0.39 \\
\hline & Control & 40 & 2.46 & 0.54 & 2.47 & 0.43 \\
\hline \multirow{2}{*}{ Mental Health } & Experimental & 40 & 1.73 & 0.24 & 1.44 & 0.17 \\
\hline & Control & 40 & 1.69 & 0.29 & 1.68 & 0.21 \\
\hline
\end{tabular}

In Table 1, the statistical indices of means and standard deviation for commitment to exercise and mental health of the experimental and control groups have been presented for the pretest and posttest stages. According to the findings from Table 1, in the posttest stage the mean of the score for commitment to exercise $(\mathrm{M}=3.54 \pm 0.39)$ for the cognitive-behavioral intervention group is larger than the mean score for commitment to exercise $(\mathrm{M}=2.47 \pm$ $0.43)$ for the control group, and the score for mental health $(\mathrm{M}=1.44 \pm 0.17)$ for the cognitive-behavioral intervention group is smaller than the mean score for mental health $(M=1.68 \pm 0.21)$ for the control group. Analysis of covariance has been used to obtain the results of the investigation of the special cognitive-behavioral intervention effect on commitment to exercise and mental health.

Table 2. Results of multiple-variable covariance for the effect of group membership

\begin{tabular}{|c|c|c|c|c|c|c|c|c|}
\hline Variables & & $\begin{array}{l}\text { Sum of } \\
\text { squares }\end{array}$ & $\begin{array}{l}\text { Degree of } \\
\text { freedom }\end{array}$ & $\begin{array}{l}\text { Mean of } \\
\text { squares }\end{array}$ & $\mathbf{F}$ & Significance & $\begin{array}{l}\text { Degree } \\
\text { of effect }\end{array}$ & $\begin{array}{l}\text { Statistic } \\
\text { al } \\
\text { power }\end{array}$ \\
\hline Pretest & Posttest & & & & & & & \\
\hline \multirow[t]{2}{*}{ Model } & $\begin{array}{l}\text { Commitment } \\
\text { To exercise }\end{array}$ & 37.999 & 4 & 9.5 & 293.81 & $0.000^{* *}$ & 0.94 & 1 \\
\hline & Mental Health & 5.097 & 4 & 1.274 & 178.9 & $0.000 * *$ & 0.905 & 1 \\
\hline \multirow{2}{*}{$\begin{array}{l}\text { Commitment } \\
\text { To exercise }\end{array}$} & $\begin{array}{l}\text { Commitment } \\
\text { To exercise }\end{array}$ & 6.67 & 1 & 6.67 & 206.3 & $0.000 * *$ & 0.73 & 1 \\
\hline & Mental Health & 0.004 & 1 & 0.004 & 0.606 & 0.43 & 0.008 & 1 \\
\hline \multirow{2}{*}{$\begin{array}{l}\text { Mental } \\
\text { Health }\end{array}$} & $\begin{array}{l}\text { Commitment } \\
\text { To exercise }\end{array}$ & 0.013 & 1 & 0.013 & 0.39 & 0.53 & 0.005 & 1 \\
\hline & Mental Health & 2.923 & 1 & 2.923 & 410.6 & $0.000 * *$ & 0.846 & 1 \\
\hline \multirow{2}{*}{$\begin{array}{l}\text { Group } \\
\text { Membership }\end{array}$} & $\begin{array}{l}\text { Commitment } \\
\text { To exercise }\end{array}$ & 16.134 & 1 & 16.134 & 539.14 & $0.000 * *$ & 0.875 & 1 \\
\hline & Mental Health & 1.304 & 1 & 1.304 & 183.18 & $0.000 * *$ & 0.71 & 1 \\
\hline \multirow[t]{2}{*}{ Error } & $\begin{array}{l}\text { Commitment } \\
\text { To exercise }\end{array}$ & 2.425 & 75 & 0.032 & & & & \\
\hline & Mental Health & 0.534 & 75 & 0.007 & & & & \\
\hline \multirow[t]{2}{*}{ Total } & $\begin{array}{l}\text { Commitment } \\
\text { To exercise }\end{array}$ & 40.424 & 79 & & & & & \\
\hline & Mental Health & 5.631 & 79 & & & & & \\
\hline
\end{tabular}

$0.875=$ commitment-to-exercise $\beta 1.0 .937=\mathrm{R} 2$ Adjusted $\mathrm{R} 2=0.94$

$\mathrm{R} 2=0.905$ adjusted R2 $=0.9$ Mental Health $\beta 1=0.71$ 
As shown in Table 2, taking into consideration the calculated coefficient $\mathrm{F}$, it can be seen that there is a significant difference between the means of the scores for commitment to exercise and mental health of both groups. Therefore, the special cognitive-behavioral intervention has helped increase the scores for commitment to exercise and mental health in the participants in the posttest for the experimental group. In view of the adjusted $\beta$ indices and level of significance of 0.01 , it can be concluded that the special cognitive-behavioral intervention carries $87.5 \%$ predictability of the employees' commitment to exercise and $71 \%$ for mental health.

$\hat{\mathrm{Y}}=0.875 \mathrm{X}_{1}+0.71 \mathrm{X} 2$

To obtain the results of the investigation on the effect of the special cognitive-behavioral intervention on mental health, analysis of covariance was used. This took into consideration the scores controlled for commitment to exercise with the results as shown in Table 3.

Table3. Results of covariance analysis for the effect of group membership on the scores for mental health in view of the scores controlled for commitment to exercise

\begin{tabular}{llllllll}
\hline Variables & $\begin{array}{l}\text { Sum of } \\
\text { squares }\end{array}$ & $\begin{array}{l}\text { Degree of } \\
\text { freedom }\end{array}$ & $\begin{array}{l}\text { Mean of } \\
\text { squares }\end{array}$ & F & Significance & $\begin{array}{l}\text { Degree of } \\
\text { Effect }\end{array}$ & $\begin{array}{l}\text { Statistical } \\
\text { power }\end{array}$ \\
\hline Models & 2.223 & 2 & 1.111 & 25.104 & $* * 0.000$ & 0.395 & $\mathbf{1}$ \\
y-intercept & 9.964 & 1 & 9.964 & 225.1 & 0.000 & 0.745 & $\mathbf{1}$ \\
Concomitant & 1.043 & 1 & 1.043 & 23.561 & $* * 0.000$ & 0.234 & $\mathbf{1}$ \\
Group Membership & 0.003 & 1 & 0.003 & 0.069 & 0.794 & 0.001 & $\mathbf{1}$ \\
Error & 3.409 & 77 & 0.044 & & & & \\
\hline Total & $\mathbf{5 . 6 3 1}$ & $\mathbf{7 9}$ & & & & & \\
\hline$\beta 2=0.234, \beta 1=0.001, R 2$ adjusted $=0.397, \mathrm{R} 2=0.395$.
\end{tabular}

As it can be seen in Table 3, regarding the coefficient F, there is no significant difference between the adjusted means of the scores for mental health of the participants in both controlled and experimental group in the posttest stage $(\mathrm{p}<0.05)$. Therefore, the adjusting role of the variable for commitment to exercise is supported.

$\hat{Y}=0 / 234 X_{1}$

\section{Discussion}

The results presented support the first hypothesis, i.e. that the special cognitive-behavioral intervention will improve the commitment to exercise and mental health. The findings of this part of the study are consistent with the results of studies by Markland and Tobin (2010) and by Ingledew et al., (2014). This suggests that counseling support has the potential to enhance the desire for exercise. Also, the results are in line with those of Brovold et al. (2012) and Millstein et al., (2016), suggesting that the relationship between these interventions enhances mental health. However, subsequent results indicated that medical recommendations contributed to adherence to exercise and mental health improvement among patients. Using special varied interventions, Markland and Tobin investigated the relation between the support for psychological needs and internalization of regular exercise behavior. In addition, Ingledew et al. studied the role of exercise motive and self-determination in doing exercise. In contrast, the findings of this study experimentally investigated the effect of the researcher-made cognitive-behavioral protocol in multiple sessions on the commitment to exercise and mental health of adults. To explain this more fully, it can be said that the fact that a considerable proportion of people have not been fully successful in adhering to exercise has added to the importance and need for interventional development (Brug, et al, 2005) based on positive thinking psychology aimed at improving the commitment to exercise among people. Normally, to achieve these aims, such socio-cognitive-behavioral theories (Ajzen, 1991) as Health Belief Model Theory, Trans-theoretical Model, Planned Behavior Theory, and Self-determination Theory can be used.

Accordingly, it seems that the special cognitive-behavioral protocol developed on the above theories by researchers can lead to improvement of commitment to exercise by using cognitive-behavioral training. Recently, smartphone applications had been developed to deliver cognitive behavioral therapy which focused on binge eating (Zhang et al., 2015a) but none of the applications focused on exercise (Zhang et al., 201b). It is important to incorporate the cognitive-behavioral intervention to promote exercise in future applications targeting at people with obesity. Further, based on the mediation model for commitment to exercise by Weiss et al. (2001) and the 
studies by Scalan et al., (2016) — who indicated that appreciation of competency for exercise affects enjoyment of exercise and is an important factor in commitment to exercise - it seems that engagement of the experimental group in physical exercises can have extra effect on commitment to exercise and mental health.

Another item which, in the opinion of the researchers, should have been addressed in the next step was whether improvement of mental health of the experimental group participants compared to that of the control group was due to the specific cognitive-behavioral intervention or due to the improvement of commitment to exercise and engagement in physical exercises. Put otherwise, will mental health continue to improve after removing the effect of commitment to exercise?

Hence, on this basis, hypothesis 2 was designed: it proposes that commitment to exercise will adjust the effect of the special cognitive-behavioral intervention on mental health. The results revealed that there was no significant effect on pretest and posttest of mental health mean scores after concomitant variable.

To explain hypothesis 2 , it can be said that it is highly probable that with a change in the evaluation of individuals' mind about the situation, exercise will improve the reasoned challenge-centered approach to stressful situations. With improved belief in their capabilities in integrating motivations and cognitive resources, exercise will enhance individuals' capability to control the unwanted effects of their perceived mental stresses (Conn, Hafdahl, Cooper, Brown, \& Lusk, 2009). Therefore, exercise may probably have extra effect on mental health. It seems that with the exclusion of the concomitant variable of commitment to exercise and the effect of commitment to exercise on mental health in this protocol, the special cognitive-behavioral intervention alone cannot significantly improve mental health in individuals.

\section{Conclusion}

Considering what was presented in explaining the hypotheses, it can be concluded that by using the researcher made cognitive-behavioral protocol based on the social cognitive-behavioral theories, commitment to doing exercises can be improved in individuals. Similarly, the mental health of participants in the experimental group improved by using the meditative role of commitment to exercise. When people do not exercise despite the risks of a sedentary lifestyle, it is optimistic to wait and see their commitment to exercise. Therefore, inevitable interventions are needed. Mere intention of exercising from knowing its benefits does not necessitate the individual's commitment to exercise. To enact this intention practically, the intervening role of commitment-to-exercise is needed. Commitment to exercise (enthusiasm for exercise, exercise intensity and frequency, reinforcing factors, and disrupting factors) seems to have positive influence on social-cognitive concepts and also fills the gap between intention and practice by improving the attitude, subjective norms, and perceived behavior control. Generally speaking, it is important to promote therapy and interventions regarding commitment to exercise when the majority of people seem to fail to exercise despite being aware of its benefits. Regular physical activities are major factors in disease prevention and physical and mental health improvement. However, the chief concern is non-adherence to regular exercises. Therefore, physicians and counselors can use the protocol of cognitive-behavioral therapy as a method to improve commitment and adherence to exercise.

Although in this study efforts were made to minimize the interfering variables and potential biases by randomly assigning the participants to the experimental and control groups, the most important limitation was failure to follow-up. Therefore, for future studies, it is recommended to ensure short-term and long-term follow-up.

As this study was conducted on Esfahan Steel Company employees with an age range of 38-56, generalization of the results to other statistical populations must be made with precaution. Therefore, it is recommended that this norm be applied not only to the statistical population of Esfahan Steel Company but also to other statistical populations - such as sick people - so that the generalization of these results and the effect of using this method can be discussed with more confidence and precision.

\section{Acknowledgements}

This study is part of a doctoral dissertation made possible by the research support of the Esfahan Steel Company. I hereby appreciate the sincere cooperation of the management and employees who worked with us on the conduction of this study.

\section{Competing Interests Statement}

The authors declare that there are no competing or potential conflicts of interest.

\section{References}

Ajzen, I. (1991). The Theory of Planned Behavior Prganizational Behavior and Human Decision Processes: Milton Keynes. England: Open University Press. 
Asztalos, M., De Bourdeaudhuij, I., \& Cardon, G. (2010). The relationship between physical activity and mental health varies across activity intensity levels and dimensions of mental health among women and men. Public health nutrition, 13(08), 1207-1214. https://doi.org/10.1017/S1368980009992825

Becker, M. H. (1974). The Health Belief Model and personal health behavior. Health Educe Monogr, 2, $324 \mathrm{e} 473$.

Brassington, G. S., Atienza, A. A., Perczek, R. E., DiLorenzo, T. M., \& King, A. C. (2002). Intervention-related cognitive versus social mediators of exercise adherence in the elderly. American journal of preventive medicine, 23(2), 80-86. https://doi.org/10.1016/S0749-3797(02)00477-4

Brickman, P., Sorrentino, R. M., \& Wortman, C. B. (1987). Commitment, conflict, and caring. Englewood Cliffs, NJ: Prentice Hall.

Brovold, T., Skelton, D. A., \& Bergland, A. (2012). The efficacy of counseling and progressive resistance home-exercises on adherence, health-related quality of life and function after discharge from a geriatric day-hospital. Archives of gerontology and geriatrics, 55(2), 453-459. https://doi.org/10.1016/j.archger.2012.01.015

Brug, J., Oenema, A., \& Ferreira, I. (2005). Theory, evidence and Intervention Mapping to improve behavior nutrition and physical activity interventions. International Journal of Behavioral Nutrition and Physical Activity, 2(1), 1. https://doi.org/10.1186/1479-5868-2-2

Clark, A., \& N. Mach (2016). Exercise-induced stress behavior, gut-microbiota-brain axis and diet: a systematic review for athletes. Journal of the International Society of Sports Nutrition, 13(1), 43. https://doi.org/10.1186/s12970-016-0155-6

Conn, V. S., Hafdahl, A. R., Cooper, P. S., Brown, L. M., \& Lusk, S. L. (2009). Meta-analysis of workplace physical activity interventions. American journal of preventive medicine, 37(4), 330-339. https://doi.org/10.1016/j.amepre.2009.06.008

Darlow, S. D., \& Xu, X. (2011). The influence of close others' exercise habits and perceived social support on exercise. Psychology of Sport and Exercise, 12(5), 575-578. https://doi.org/10.1016/j.psychsport.2011.04.004

Deci, E. L., \& Ryan, R. M. (2008). Facilitating optimal motivation and psychological well-being across life's domains. Canadian Psychology/Psychologie $\quad$ canadienne, $\quad 49(1), \quad 14$ https://doi.org/10.1037/0708-5591.49.1.14

Deforche, B., \& De Bourdeaudhuij, I. (2015). Attentional distraction during exercise in overweight and normal-weight boys. International journal of environmental research and public health, 12(3), 3077-3090. https://doi.org/10.3390/ijerph120303077

Derakhshanpoor, A., Vaez Mousavi, S. M. K., \& Taheri, H. R. (2016). Introducing the Questionnaire of Commitment to Exercise. Global Journal of Health Science, 9(6), 151. https://doi.org/10.5539/gjhs.v9n6p151

El-Kade, S. M. A., \& Al-Jiffri, O. H. (2016). Exercise alleviates depression related systemic inflammation in chronic obstructive pulmonary disease patients. African health sciences, 16(4), 1078-1088. https://doi.org/10.4314/ahs.v16i4.25

Epstein, N. B., \& Baucom, D. H. (2002). Enhanced cognitive-behavioral therapy for couples: A contextual approach. New York: American Psychological Association. https://doi.org/10.1037/10481-000

Fuss, J., Steinle, J., Bindila, L., Auer, M. K., Kirchherr, H., Lutz, B., \& Gass, P. (2015). A runner's high depends on cannabinoid receptors in mice. Proceedings of the National Academy of Sciences, 112(42), 13105-13108. https://doi.org/10.1073/pnas.1514996112

Goldberg, D. P., \& Hillier, V. F. (1979). A scaled version of the General Health Questionnaire. Psychological medicine, 9(01), 139-145. https://doi.org/10.1017/S0033291700021644

Haskell, W. L., Lee, I.-M., Pate, R. R., Powell, K. E., Blair, S. N., Franklin, B. A., . . Bauman, A. (2007). Physical activity and public health: updated recommendation for adults from the American College of Sports Medicine and the American Heart Association. Circulation, $116(9), \quad$ https://doi.org/10.1249/mss.0b013e3180616b27

Ho, R., Neo, L. F., Chua, A., Cheak, A., \& Mak, A. (2010). Research on psychoneuroimmunology: does stress influence immunity and cause coronary artery disease. Ann Acad Med Singapore, 39(3), 191-196.

Ingledew, D. K., Markland, D., \& Medley, A. R. (1998). Exercise motives and stages of change. Journal of Health 
Psychology,3, 477-489. https://doi.org/10.1177/135910539800300403

Jouper, J., \& Hassmén, P. (2009). Exercise intention, age and stress predict increased qigong exercise adherence. Journal of bodywork and movement therapies, 13(2), 205-211. https://doi.org/10.1016/j.jbmt.2008.08.002

Krejcie, R. V., \& Morgan, D. W. (1970). Determining sample size for research activities. Educational and psychological measurement, 30(3), 607-610. https://doi.org/10.1177/001316447003000308

Liu, Y., Ho, R. C.-M., \& Mak, A. (2012). Interleukin (IL)-6, tumour necrosis factor alpha (TNF- $\alpha$ ) and soluble interleukin-2 receptors (sIL-2R) are elevated in patients with major depressive disorder: a meta-analysis and meta-regression. Journal of affective disorders, 139(3), 230-239. https://doi.org/10.1016/j.jad.2011.08.003

Lu, Y., Ho, C. S., Liu, X., Chua, A. N., Wang, W., McIntyre, R. S., \& Ho, R. C. (2017). Chronic administration of fluoxetine and pro-inflammatory cytokine change in a rat model of depression. PloS one, 12(10), e0186700. https://doi.org/10.1371/journal.pone.0186700

Manuela Crispim Nascimento, C., Rodrigues Pereira, J., Pires de Andrade, L., Garuffi, M., Leme Talib, L., Vicente Forlenza, O., ... Stella, F. (2014). Physical exercise in MCI elderly promotes reduction of pro-inflammatory cytokines and improvements on cognition and BDNF peripheral levels. Current Alzheimer Research, 11(8), 799-805. https://doi.org/10.2174/156720501108140910122849

Markland, D., \& Tobin, V. J. (2010). Need support and behavioural regulations for exercise among exercise referral scheme clients: The mediating role of psychological need satisfaction. Psychology of Sport and Exercise, 11(2), 91-99. https://doi.org/10.1016/j.psychsport.2009.07.001

Middelkamp, J., van Rooijen, M., Wolfhagen, P., \& Steenbergen, B. (2017). The effects of a self-Efficacy intervention on exercise behavior of fitness club members in 52 weeks and long-term relationships of transtheoretical model constructs. Journal of sports science \& medicine, 16(2), 163.

Millstein, R. A., Celano, C. M., Beale, E. E., Beach, S. R., Suarez, L., Belcher, A. M., . . Huffman, J. C. (2016). The effects of optimism and gratitude on adherence, functioning and mental health following an acute $\begin{array}{llll}\text { coronary syndrome. } \quad \text { General Hospital } & \text { Psychiatry, } & \text { 43, }\end{array}$ https://doi.org/10.1016/j.genhosppsych.2016.08.006

Palahang, H., Nasr, M., \& Shahmohammadi, D. (1996). Epidemiology of mental illnesses in Kashan city. Iranian Journal of Psychiatry and clinical Psychology, 2(4), 19-27.

Quek, Y. H., Tam, W. W., Zhang, M. W., \& Ho, R. (2017). Exploring the association between childhood and adolescent obesity and depression: a meta - analysis. Obesity Reviews, 18(7), 742-754. https://doi.org/10.1111/obr.12535

Richard, M., et al. (1997). Intrinsic motivation and exercise adherence. Int J Sport Psychol, 28(4), 335-354.

Ryan, R. M., \& Deci, E. L. (2000). Self-determination theory and the facilitation of intrinsic motivation, social development, and well-being. American psychologist, 55(1), 68. https://doi.org/10.1037/0003-066X.55.1.68

Scanlan, T. K., Russell, D. G., Magyar, T. M., \& Scanlan, L. A. (2009). Project on elite athlete commitment (PEAK): III. An examination of the external validity across gender, and the expansion and clarification of the sport commitment model. Journal of Sport and Exercise Psychology, 31, 685-705. https://doi.org/10.1123/jsep.31.6.685

Scanlan, T. K., Russell, D. G., Magyar, T. M., \& Scanlan, L. A. (2009). Project on elite athlete commitment (PEAK): III. An examination of the external validity across gender, and the expansion and clarification of the sport commitment model. Journal of Sport and Exercise Psychology, 31, 685-705. https://doi.org/10.1123/jsep.31.6.685

Snyder, C., Cheavens, J. S., \& Michael, S. T. (2005). Hope Theory: History and Elaborated Model. In J. Elliot (Ed.), Interdisciplinary Perspectives on Hope, Hauppauge (pp. 219-223). NY: Nova Science Publishers.

Sousa, C., Torregrosa, M., Viladrich, C., Villamarín, F., \& Cruz, J. (2007). The commitment of young soccer players. Psicothema, 19(2), 256-262.

Stonerock, G. L. \& Blumenthal, J. A. (2017). Role of counseling to promote adherence in healthy lifestyle medicine: strategies to improve exercise adherence and enhance physical activity. Progress in cardiovascular diseases, 59(5), 455-462. https://doi.org/10.1016/j.pcad.2016.09.003

Sukhodolsky, D. G., Kassinove, H., \& Gorman, B. S. (2004). Cognitive-behavioral therapy for anger in children and adolescents: A meta-analysis. Aggression and violent behavior, 9(3), 247-269. 
https://doi.org/10.1016/j.avb.2003.08.005

Tiedemann, A., Sherrington, C., \& Lord, S. R. (2011). Predictors of exercise adherence in older people living in retirement villages. Preventive medicine, 52(6), 480-481. https://doi.org/10.1016/j.ypmed.2011.03.015

Veale, D. (1987). Exercise and mental health. Acta Psychiatrica Scandinavica, 76(2), 113-120. https://doi.org/10.1111/j.1600-0447.1987.tb02872.x

Weiss, M. R., Kimmel, L. A., \& Smith, A. L. (2001). Determinants of sport commitment among junior tennis players: Enjoyment as a mediating variable. Pediatric Exercise Science, 13(2), 131-144. https://doi.org/10.1123/pes.13.2.131

Yang, J. L., Liu, D. X., Jiang, H., Pan, F., Ho, C. S., \& Ho, R. C. (2016). The effects of high-fat-diet combined with chronic unpredictable mild stress on depression-like behavior and leptin/leprb in male rats. Scientific reports, 6, 35239. https://doi.org/10.1038/srep35239

Zhang, M. W., Ho, R., Cassin, S. E., Hawa, R., \& Sockalingam, S. (2015). Online and smartphone based cognitive behavioral therapy for bariatric surgery patients: Initial pilot study. Technology and Health Care, 23(6), 737-744. https://doi.org/10.3233/THC-151026

Zhang, M. W., Ho, R. C., Hawa, R., \& Sockalingam, S. (2016). Analysis of the information quality of bariatric surgery smartphone applications using the silberg scale. Obesity surgery, 26(1), 163-168. https://doi.org/10.1007/s11695-015-1890-5

\section{Copyrights}

Copyright for this article is retained by the author(s), with first publication rights granted to the journal.

This is an open-access article distributed under the terms and conditions of the Creative Commons Attribution license (http://creativecommons.org/licenses/by/4.0/). 